Research Article

\title{
Experimental Study on Methane Desorption from Lumpy Coal under the Action of Hydraulic and Thermal
}

\author{
Dong Zhao ${ }^{1 D},{ }^{1}$ Dayuan Li, ${ }^{1}$ Yulin $\mathrm{Ma}^{2}$ Zengchao Feng, ${ }^{1,3}$ and Yangsheng Zhao ${ }^{1,3}$ \\ ${ }^{1}$ College of Mining Engineering, Taiyuan University of Technology, Taiyuan, China \\ ${ }^{2}$ School of Mechanics and Engineering, Liaoning Technical University, Fuxin, China \\ ${ }^{3}$ Institute of Mining Technology, Taiyuan University of Technology, Taiyuan, China \\ Correspondence should be addressed to Dong Zhao; zhaodong@tyut.edu.cn
}

Received 25 December 2017; Accepted 22 February 2018; Published 30 April 2018

Academic Editor: Claudio Pettinari

Copyright ( $\odot 2018$ Dong Zhao et al. This is an open access article distributed under the Creative Commons Attribution License, which permits unrestricted use, distribution, and reproduction in any medium, provided the original work is properly cited.

\begin{abstract}
Moisture and thermal are the key factors for influencing methane desorption during CBM exploitation. Using high-pressure water injection technology into coalbed, new fractures and pathways are formed to transport methane. A phenomenon of waterinhibiting gas flow existed. This study is focused on various water pressures impacted on gas-adsorbed coal samples, and then the desorption capacity could be revealed under different conditions. And the results are shown that methane desorption capacity was decreased with the increase in water pressure at room temperature and the downtrend would be steady until water pressure was large enough. Heating could promote gas desorption capacity effectively, with the increasing of water injection pressures, and the promotion of thermal on desorption became more obvious. These results are expected to provide a clearer understanding of theoretical efficiency of heat water or steam injection into coalbed, and they can provide some theoretical and experimental guidance on CBM production and methane control.
\end{abstract}

\section{Introduction}

Coalbed methane, CBM, is a significant natural energy resource and plays an important role in the structure of clean and new energy in China. However, currently, China CBM cannot satisfy requirements for effective and efficient recovery due to low permeability, low reservoir pressure, and high gas adsorption capacity [1]. With increased mining depth, ground stress, and gas pressure, as well as low gas permeability of coal seams, the gas extraction became difficult before mining [2]. The decrease in gas pressure during gas immigration can lead to gas desorption and cause matrix contraction, leading to fracture extension and further improving the permeability of the coal seam [3].

Furthermore, their permeability in the gas discharge process is complicated and can be affected by the coupled processes of gas migration and deformation of the coalbed. The mechanism of coupled flow and deformation on CBM recovery has drawn immense attention and significant achievements [4]. To increase coal seam permeability and reduce the amount of extraction drilling and risk of outburst, researchers studied techniques and methods of hydraulics. These methods include ordinary drill, enhanced drills, coalbed water injection, hydraulic punching, hydraulic cutting, and hydraulic fracturing, and they are widely used in modern coal mining to improve coalbed permeability and gas output. All these processes are including high-pressure water. Thus, if highpressure water has been injected into coalbed, the desorption capacity of methane would be effected due to moisture [5].

Some researchers have engaged in this field in order to improve coalbed permeability and amount of gas output. The two major technologies are hydraulic fracture and thermal injection.

Hydraulic fracture will increase the moisture content in coalbed which it is resulting from water injection. According to the mechanism of moisture increased in coalbed, many scholars have performed studies on the influence of moisture on methane desorption $[6,7]$, but they wet the coal samples before the experiment. Some scholars realized that injecting water would destroy the statement for gas adsorption 


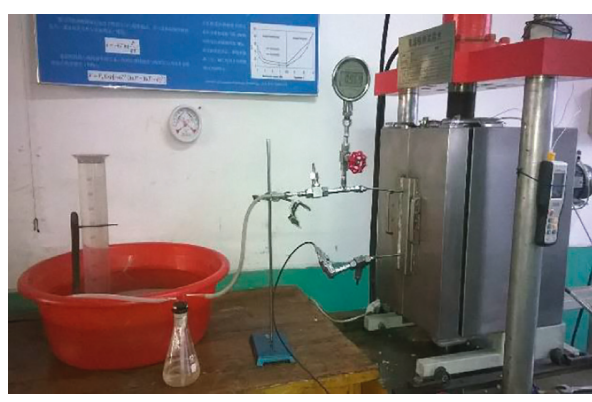

(a)

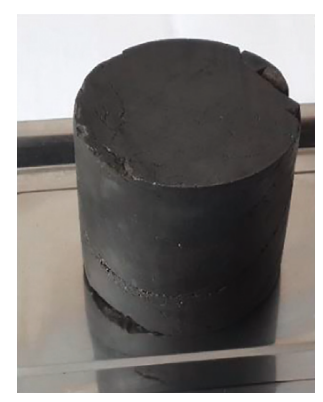

(b)

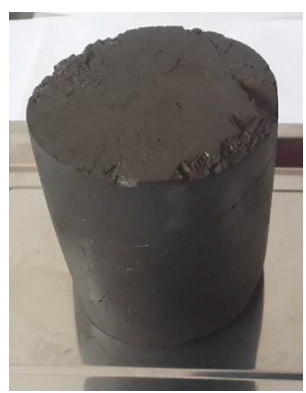

(c)

FiguRE 1: Experimental apparatus and coal samples used in these experiments. (a) Experimental apparatus. (b) Coal sample \#1. (c) Coal sample \#2.

$[5,8-11]$, and they designed the ideal experimental process in which water was injected into the dry coal samples under the equilibrium state of gas absorption. All of these results showed that the maximum desorption quantity decreases gradually with the amount of injected water, but they were not considering different water pressures that impacted on the same or different equilibrium gas adsorption state.

Thermal injection is a new technology in CBM exploitation, and they have been successfully applied to the enhancement of coalbed methane recovery [12-16]. Thermal simulation technologies, such as alternative or supplementary methods for the enhancement of gas production from unconventional reservoirs, have gained great attention in recent years. For example, electromagnetic materials, hot water injection, hot gas injection, and microwave or radio have been used [17-19]. Methane desorption rate would be improved by coalbed heating, but the injected water could block the channels of gas flow imposing additional resistance on the transport and production of coalbed methane. Instead of hot water or superheated steam, the hot gas injection method would induce a binary gas flow and make the forecasting of gas production more difficult.

In this paper, a proposal about heat and water injection technology to improve coalbed methane production has been proposed. By combining high-pressure water that blocks gas desorption and heat that accumulates gas output, a series of experiments on methane-bearing coal samples with water injection at different water and gas pressure were performed. And then after natural desorption under water injection, the coal samples were heated. After that, desorption capacities of the coal samples at different water injection pressures and thermal effects have been illustrated. The experiments on constant and warming temperature of the desorption character of gassy coal under different water injection pressures were carried out. These results are expected to provide a clearer understanding of theoretical efficiency of heat water or steam injection into coalbed, and they can provide some theoretical and experimental guidance on CBM production and coal mine methane control.

\section{Methods}

2.1. Coal Samples and Preparation. Coal samples used in experiments were taken from Gucheng and Gaohe Coal
TABLe 1: Analysis results of experimental coal.

\begin{tabular}{lccccc}
\hline & & & \multicolumn{3}{c}{ The volatile } \\
Name of coal & $\begin{array}{c}R_{\text {omax }} \\
\text { samples }\end{array}$ & $\begin{array}{c}M_{\text {ad }} \\
(\%)\end{array}$ & $\begin{array}{c}A_{\mathrm{d}} \\
(\%)\end{array}$ & $\begin{array}{r}V_{\text {ad }} \\
(\%)\end{array}$ & $\begin{array}{c}V_{\text {daf }} \\
(\%)\end{array}$ \\
\hline Gucheng (\#1) & 2.26 & 1.05 & 10.14 & 11.82 & 13.35 \\
Gaohe (\#2) & 2.02 & 1.08 & 8.69 & 14.02 & 15.52 \\
\hline
\end{tabular}

$R_{\text {omax }}$ : vitrinite reflectance; $M_{\text {ad }}:$ moisture content; $A_{\mathrm{d}}$ : ash content; $V_{\text {ad }}:$ air drying base-volatile matter content; $V_{\text {daf }}$ dry ash-free basis volatile matter content.

Mine which were belonging to number 3 coal seam of Qinshui Coalfield in Lu'an Mining Area. Large coal samples were taken from the well and wax sealed on site. After reaching the laboratory, they were processed into $\Phi 100 \mathrm{~mm} \times 100 \mathrm{~mm}$ cylindrical specimens. The picture of the experimental coal samples is shown in Figure 1, and the results of proximate and reflectance analysis are shown in Table 1.

The samples are lumpy, which contained similar pores and fractures to a coalbed. Pores are the dominant place for gas storage and fractures for gas transportation. Methane adsorbed on the coal samples was used for CBM in situ, and enclosed CBM was simulated using water injection after adsorption.

2.2. Experimental Apparatus. To study the adsorption/ desorption characteristics of coal mass samples and to carry out simulated water injection CBM experiments, we constructed a new experimental system. The setup comprises a stainless steel container that withstands pressures up to $20 \mathrm{MPa}$ and has top and bottom openings with flexible seals. The top part is used to inject and produce gas, and the bottom part is used to inject water. A columnar coal sample is placed inside the container, which is surrounded by a temperature-controlled air bath. Water injection and gas production in the apparatus are similar to the one water injection well per gas production well configuration under ideal conditions. The coal mass samples simulate an ideal coalbed after hydrofracture. Gas usually desorbs rapidly, but once water is injected, the process slows down and becomes less efficient. A series of experiments was performed at 


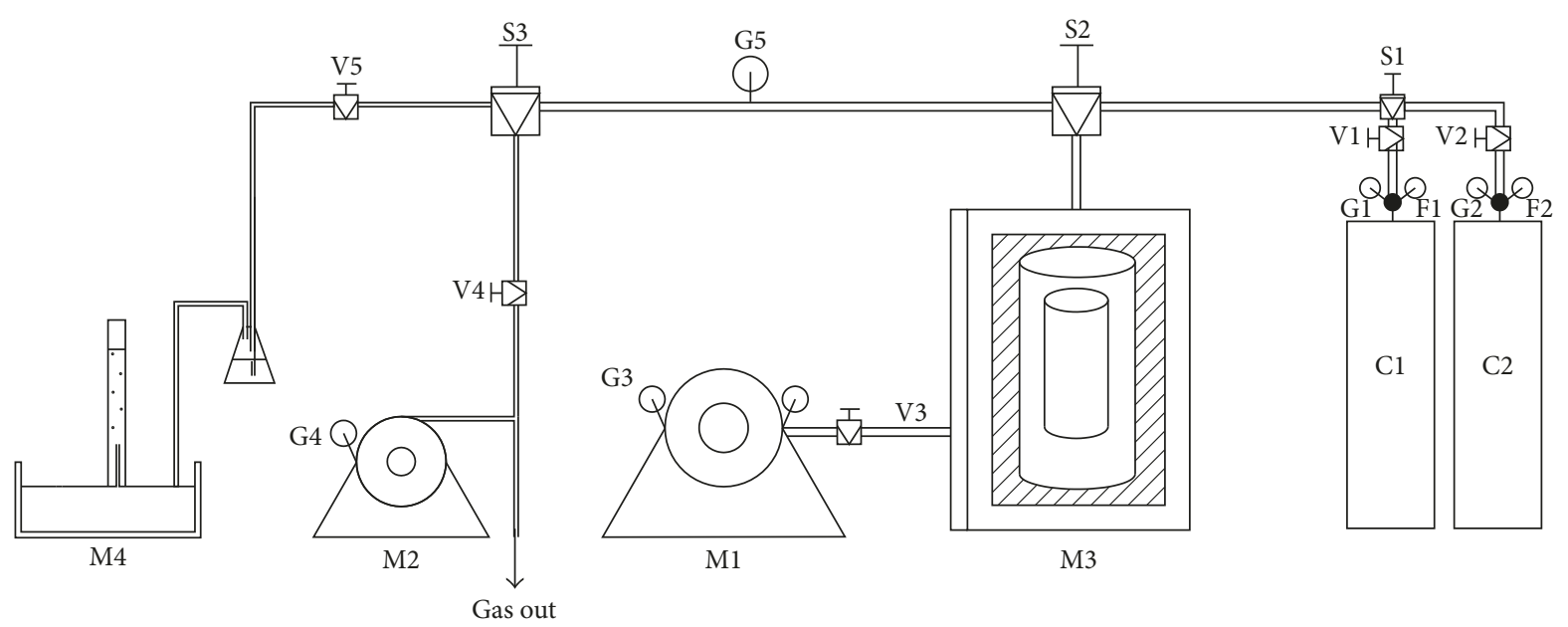

FIGURE 2: Schematic diagram of the experimental apparatus used in this study. $\mathrm{C} 1$ and $\mathrm{C} 2$ : methane $\left(\mathrm{CH}_{4}\right)$ and helium $(\mathrm{He})$ cylinder storage; F1 and F2: flow of gas; G1, G2, and G3: gauge for displaying the pressure of methane, helium, and water, respectively; G4: negative gauge for air pressure used for vacuum; G5: gauge for sample gas pressure; V1, V2, V3, V4, and V5: needle valves; S1, S2, and S3: three-port valves; M1: water injection pump; M2: vacuum pump; M3: temperature-controlling device; M4: measurement system.

different water pressures to determine the desorption behavior. The appearance and the schematic diagram of the experimental apparatus are shown in Figures 1 and 2, respectively.

The gas system indicates the gas flow path, and the liquid system introduces water at different pressures into gasbearing samples. The system is controlled based on the experimental conditions, including pressure and flow. Needle valves (V1, V2, and V3) and gauges (G1, G2, and G3) are used to regulate and show the pressure of methane $\left(\mathrm{CH}_{4}\right)$, helium $(\mathrm{He})$, and water, respectively, and flowmeters (F1 and F2) are used to read the gas and liquid flow rate. In addition, a switch valve (S1) is used to switch from methane to helium. Methane, the major CBM component, is supplied from a high-pressure cylinder (C1). Helium from cylinder C2 is used to check for leaks and measure free volume after sampling in the container. Then, helium was purged using a vacuum pump (M2) until the sample column contained no gas before methane injection. It would last more than $48 \mathrm{~h}$.

After testing for leaks and methane injection (the equilibrium pressure is shown on G5), liquid water was injected from the bottom until the container was full of water. This process simulates an ideal coalbed by injecting water around the surface of broken coal at a certain pressure. An injection device (M1) is used to inject liquid water. The injected water was left in place for approximately $24 \mathrm{~h}$ to simulate ideal water-bearing coal after hydrofracture.

A control device (M3) was used to regulate the temperature via an air circulation system. The system for measuring water outflow consisted of a conical measuring flask to measure the flow volume during desorption. A gas collection system (M4), using displacement of water and a rotor flowmeter, was used to precisely determine the volume of desorbed methane (precision $\pm 2 \mathrm{~mL}$ ).

2.3. Experimental Procedures. During the experiments, the coal samples were placed in adsorption-water injection- desorption apparatus at a room temperature of $25^{\circ} \mathrm{C}$ which means coal reservoir temperature and later up to $90^{\circ} \mathrm{C}$ which is experimental temperature controlled by a temperature controller using thermal air flow. Before the experiment, the free volume of coal in the container is measured. The experimental procedures are divided into three steps.

The first is the adsorption, check the airtightness of the experimental device by the method of high-pressure helium and then keep the device vacuum under airtightness more than $48 \mathrm{~h}$, and finally open the valve for connecting the gas container with sample container so that the coal sample could adsorb gas. The process would last for 3 to 7 days until the gas pressure is constant. Under the rated adsorption pressure, the pressure change during the adsorption process is recorded by the digital pressure gauge.

The second is the high-pressure water injection, connecting M1 to M3 after coal sample adsorption reached an equilibrium state. The water pressure is controlled by the water pump in M1 and divided into four different pressures: they are water pressure equal to gas pressure (1 time), 2.5 times of gas pressure (2.5 times), 6.25 times of gas pressure (6.25 times), and 16 times of gas pressure (16 times). For contrast, natural desorption without water injection after adsorption is necessary. During the water injecting process, water has run through the entire coal sample. Then, the state of water in the coal sample container was maintained for $24 \mathrm{~h}$. This process is simulated to moisture injection in situ coal seam.

The third is the desorption, and it is separated into two different steps: the one is room temperature desorption and the other is heating to $90^{\circ} \mathrm{C}$ for desorption. M4 is connected to $\mathrm{M} 3$ for desorption under atmospheric pressure. The desorption process would last $48 \mathrm{~h}$ in each experiment, and the desorption gas is collected. The amount of gas desorption is measured in real time during the experiment and after less than $10 \mathrm{~mL} / \mathrm{h}$, and it is considered that the desorption equilibrium has been reached. 
TABLE 2: Raw data of the two coal samples at gas adsorption pressure around 0.25 MPa.

\begin{tabular}{|c|c|c|c|c|c|c|c|c|c|c|c|c|c|}
\hline Experimental stage & $\begin{array}{l}\text { Sample } \\
\text { number }\end{array}$ & $\begin{array}{c}\Delta P \\
(\mathrm{MPa})\end{array}$ & $\begin{array}{c}P_{1} \\
(\mathrm{MPa})\end{array}$ & $V_{1}(\mathrm{~L})$ & $\begin{array}{c}P_{2} \\
(\mathrm{MPa})\end{array}$ & $m_{1}(\mathrm{~g})$ & $m_{2}(\mathrm{~g})$ & $\omega(\%)$ & $V_{2}(\mathrm{~L})$ & $V_{3}(\mathrm{~L})$ & $V_{4}(\mathrm{~L})$ & $\begin{array}{c}d V_{5} \\
(\mathrm{~mL} / \mathrm{g})\end{array}$ & $\eta_{\max }$ \\
\hline \multirow{2}{*}{ Natural desorption } & 1 & & 0.295 & & - & 1101 & - & 0 & & 272.63 & 4110.87 & 3.73 & 0.3477 \\
\hline & 2 & 0.11 & 0.241 & 1782.03 & - & 1074 & - & 0 & 102.02 & 242.73 & 4140.77 & 3.65 & 0.3717 \\
\hline \multirow{3}{*}{$\begin{array}{l}1 \text { time of adsorption } \\
\text { pressure (about } \\
0.25 \mathrm{MPa} \text { ) }\end{array}$} & 1 & & 0.215 & & 0.222 & 1101 & - & 1.455 & .86 & 199.21 & & 3.43 & 0.114 \\
\hline & $1_{2}$ & 0.1 & 0.215 & 2400.68 & 0.222 & 1101 & 1117.02 & 1.455 & 93.86 & 199.21 & 378 & 3.43 & 0.5815 \\
\hline & 2 & 0.11 & 0.230 & 1116.07 & 0.230 & 1074 & 1090.93 & 1.576 & 113.15 & 256.9 & & 3.84 & 0.2082 \\
\hline \multirow{3}{*}{$\begin{array}{l}2.5 \text { times of adsorption } \\
\text { pressure (about } \\
0.625 \mathrm{MPa})\end{array}$} & 1 & & 0.195 & & 0.5 & & & & & & & 5 & \\
\hline & $1_{2}$ & 0.1 & 0.195 & & 0.508 & 1101 & 1112.66 & 1.144 & & & & 45 & 0.2858 \\
\hline & 2 & 0.105 & 0.182 & 441.14 & 0.458 & 1074 & 1089.24 & 1.41 & 101.95 & 183.18 & 4001.07 & 3.72 & 0.0644 \\
\hline \multirow{3}{*}{$\begin{array}{l}6.25 \text { times of adsorption } \\
\text { pressure (about } \\
1.56 \mathrm{MPa} \text { ) }\end{array}$} & 1 & & 0.225 & & 1.25 & 1101 & - & 1.57 & & & & 3.42 & \\
\hline & $1_{2}$ & & 0.225 & & 1.2 & & & 1.57 & & & & & \\
\hline & 2 & 0.11 & 0.196 & & 1.2 & 1074 & 1090.13 & 1.502 & & & & 3.89 & 0.0272 \\
\hline \multirow{3}{*}{$\begin{array}{l}16 \text { times of adsorption } \\
\text { pressure (about } \\
4.00 \mathrm{MPa} \text { ) }\end{array}$} & 1 & 0.1 & 0.215 & 269.02 & 3.212 & & - & & & & & 3.43 & 0.0192 \\
\hline & $1_{2}$ & & 0.215 & & 3.212 & 1101 & 1114.77 & 1.251 & & 199.21 & & & 0.2162 \\
\hline & 2 & 0.11 & 0.195 & 211.36 & 3.223 & 1074 & 1091.24 & 1.605 & 102.02 & 196.40 & 4187.1 & 3.89 & 0.0271 \\
\hline
\end{tabular}

Note. $\Delta P$ is the $D$ value between initial and final gas pressures of the gas storage tank, which the content of $3.8 \mathrm{~L} ; P_{1}$ is the gas adsorption pressure at final stage; $V_{1}$ is the desorption volume of the coal sample at each stage; $P_{2}$ is the water injection pressure; it depends on final gas adsorption pressure; $V_{2}$ is the free content after coal into the sample container; it is measured by helium; $m_{1}$ is the mass of the dry coal sample; $m_{2}$ is the mass of the wet coal sample after water injection and desorption; $\omega$ is the moisture content of the coal sample appending on dry coal after water injection and desorption; $V_{3}$ and $V_{4}$ are the free gas volume and adsorption gas volume, respectively; $d V_{5}$ means adsorption gas volume per unit mass of coal; $\eta_{\max }$ is accumulative desorption rate after $48 \mathrm{~h}$ desorption. All data are converted to the value at standard status $(273.15 \mathrm{~K}, 1 \mathrm{~atm})$.

TABLE 3: Raw data of the two coal samples at gas adsorption pressure around 0.50 MPa.

\begin{tabular}{|c|c|c|c|c|c|c|c|c|c|c|c|c|c|}
\hline Experimental stage & $\begin{array}{l}\text { Sample } \\
\text { number }\end{array}$ & $\begin{array}{c}\Delta P \\
(\mathrm{MPa})\end{array}$ & $\begin{array}{c}P_{1} \\
(\mathrm{MPa})\end{array}$ & $V_{1}(\mathrm{~L})$ & $\begin{array}{c}P_{2} \\
(\mathrm{MPa})\end{array}$ & $m_{1}(\mathrm{~g})$ & $m_{2}(\mathrm{~g})$ & $\omega(\%)$ & $V_{2}(\mathrm{~L})$ & $V_{3}(\mathrm{~L})$ & $V_{4}(\mathrm{~L})$ & $\begin{array}{c}d V_{5} \\
(\mathrm{~mL} / \mathrm{g})\end{array}$ & $\eta_{\max }$ \\
\hline \multirow{2}{*}{ Natural desorption } & 1 & & 0.459 & & - & & - & 0 & & & & 6.85 & \\
\hline & 2 & & & & - & & & 0 & & & & & \\
\hline \multirow{3}{*}{$\begin{array}{l}1 \text { time of adsorption } \\
\text { pressure (about } 0.25 \mathrm{MPa} \text { ) }\end{array}$} & 1 & & & & & & - & & & & & & \\
\hline & $1_{2}$ & 18 & 0.535 & & 0.5 & & 1115.3 & & & & & 6. & \\
\hline & 2 & 0.2 & 0.505 & 2354.4 & 0.5 & 1074 & 1090.2 & 1.512 & 2.02 & 508 & & 6.94 & 0.2473 \\
\hline \multirow{3}{*}{$\begin{array}{l}2.5 \text { times of adsorption } \\
\text { pressure (about } 0.625 \mathrm{MPa} \text { ) }\end{array}$} & 1 & 0185 & 0.528 & 1129.8 & 1.32 & & - & & & & & 6.25 & \\
\hline & $1_{2}$ & 105 & 0.528 & 4855 & 1.3 & & 1114.9 & & & 9.22 & & 6. & \\
\hline & 2 & & & & & & & & & & & 6. & \\
\hline \multirow{3}{*}{$\begin{array}{l}6.25 \text { times of adsorption } \\
\text { pressure (about } 1.56 \mathrm{MPa} \text { ) }\end{array}$} & 1 & 0.18 & 0.611 & 100 & 3.8 & & - & & & & & 6.1 & 0.06 \\
\hline & $1_{2}$ & & & & 3.82 & 1101 & 1116 & 1.362 & 93.86 & & & 6.00 & 0.6111 \\
\hline & 2 & 0.2 & 0.5 & 979 & 3.12 & 1074 & 1092.6 & 1.732 & 84.73 & 418.23 & 7551.76 & 7.03 & 0.0742 \\
\hline \multirow{3}{*}{$\begin{array}{l}16 \text { times of adsorption } \\
\text { pressure (about } 4.00 \mathrm{MPa} \text { ) }\end{array}$} & 1 & 0.185 & 0.495 & 700.31 & 8 & 110 & - & 1.306 & 93.86 & 458. & 6714.34 & 6.09 & 0.0474 \\
\hline & $1_{2}$ & & & & 8 & & & & & & & 6.09 & 0.47 \\
\hline & 2 & 0.2 & 0.488 & 944.65 & 8 & 1074 & 1092.5 & 1.723 & 102.02 & 491.51 & 7478.48 & 6.96 & 0.0556 \\
\hline
\end{tabular}

\section{Experimental Results}

3.1. Raw Data of Experiments. Tables 2 and 3 show the raw data of adsorption, water injection, and desorption of the coal sample, in which $\# 1, \# 2$, and $\# 1_{2}$ coal samples represent desorption of the Gucheng coal sample at $25^{\circ} \mathrm{C}$, desorption of the Gaohe coal sample at $25^{\circ} \mathrm{C}$, and desorption of the Gucheng coal sample at $90^{\circ} \mathrm{C}$, respectively. The definitions of the parameters are shown in Table 2. The data of gas adsorption pressure around $0.25 \mathrm{MPa}$ and $0.5 \mathrm{MPa}$ are shown in Tables 2 and 3, respectively.

\subsection{Analyses for Experimental Results}

3.2.1. Results of Desorption at $25^{\circ} \mathrm{C}$ and $90^{\circ} \mathrm{C}$. The curves of desorption capacity versus time in different water injection pressures for the two coal samples at adsorption pressure around $0.25 \mathrm{MPa}$ and $0.50 \mathrm{MPa}$ are shown in Figures 3 and 4, respectively. The desorption stage of coal sample \#1 had separated into two stages: the first is $25^{\circ} \mathrm{C}$ and the second is $90^{\circ} \mathrm{C}$; the two stages are continuous. And the stage of coal sample \#2 only had one stage: just $25^{\circ} \mathrm{C}$ desorption. The results of the two samples could be contrasted with different desorption stages.

As shown in Figure 3, under the condition of room temperature of $25^{\circ} \mathrm{C}$, the desorption percentage of adsorption gas is increased with time rapidly. (Desorption percentage is the proportion of desorption gas and whole adsorbed gas in real time.) The instantaneous desorption rate of all the experiments reaches the final desorption rate of $71.53 \%$ in 500 minutes. The instantaneous desorption rate of gas after injection is not obvious with time increase, the data in slow growth with time. The larger the injection 


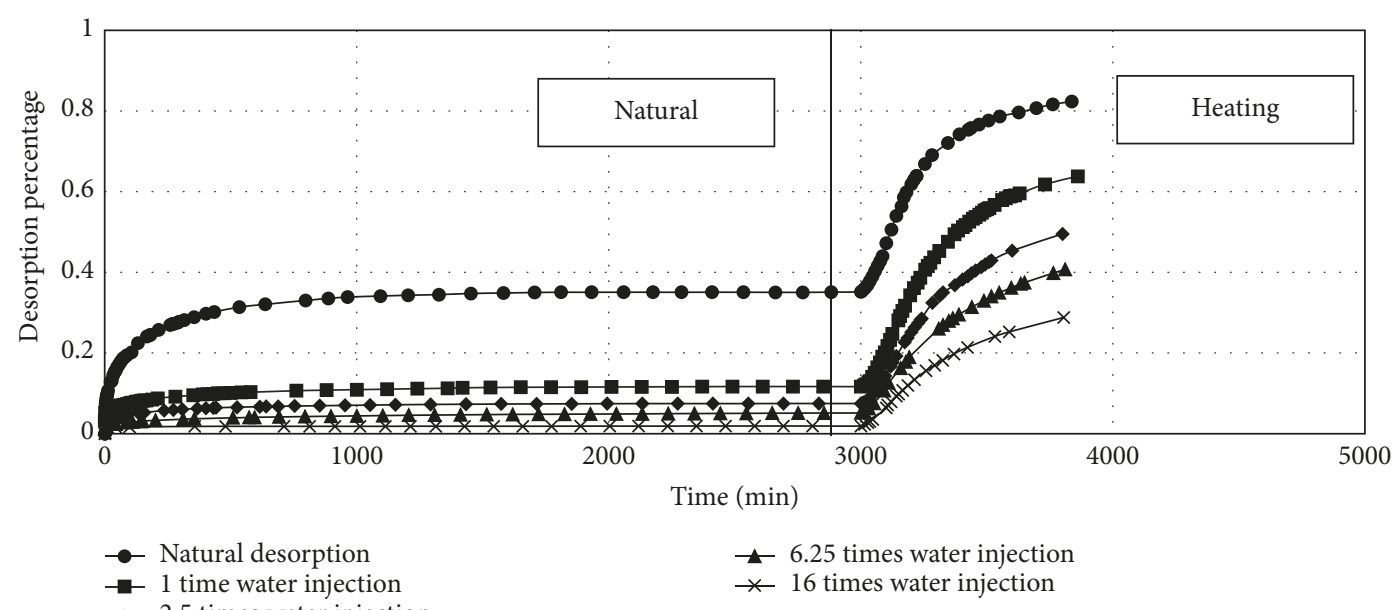

(a)

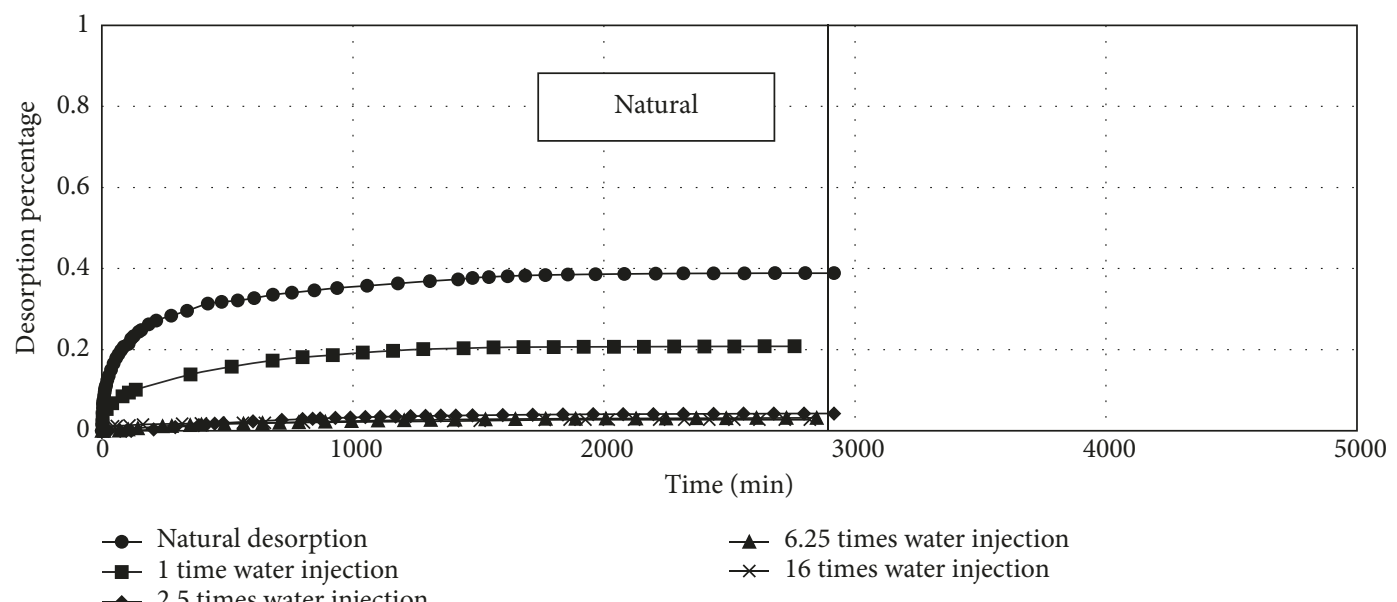

(b)

Figure 3: Desorption capacity versus time in different water injection pressures at $0.25 \mathrm{MPa}$ gas adsorption pressure. (a) Coal sample \# 1 (Gucheng Coal Mine). (b) Coal sample \#2 (Gaohe Coal Mine).

pressure, the more difficult the desorption, the lower the final desorption percentage.

In the same coal sample, with the increase of adsorption pressure, whether in natural desorption or water injection desorption, the final gas desorption percentage of the sample has been improved to some extent. When using 2 times of former adsorption pressure in Figure 4, desorption percentage of Gucheng and Gaohe coal samples increased by $11.44 \%$ and $27.82 \%$ in natural desorption. Water injection pressure is higher, and the increase of adsorption pressure on gas desorption rate is more obvious in water injection desorption. Under 16 times of water injection pressure, contrast with $0.25 \mathrm{MPa}$ gas pressure, the desorption percentage of Gucheng and Gaohe coal samples increased by 2.473 times and 2.047 times, respectively.

When the temperature rises to $90^{\circ} \mathrm{C}$, the Gucheng coal sample showed a significant increase in the desorption rate of coal methane compared with $25^{\circ} \mathrm{C}$ when water injection pressure and adsorption pressure were constant. The final desorption percentage at $90^{\circ} \mathrm{C}$ increased by 1.331 times compared with that at $25^{\circ} \mathrm{C}$ in natural desorption. With the increase of water injection pressure, the effect of heating on desorption rate increased significantly. At 16 times of water injection pressure, thermal promotes the desorption, and the gas desorption rate increased by 10.72 times which is compared to room temperature. This shows that thermal could enhance the ability of coal methane desorption effectively, and inhibition effect of water injection weakens.

The time effect of desorption in the process of mining coalbed methane is a very important indicator, which is the direct influence factor of the recovery efficiency. Therefore, based on the description of the desorption capacity of coalbed methane with the change of time, [5] uses the following formula to analyze the relationship between desorption rate and time under different conditions:

$$
\eta=\eta_{\max }\left\{1-\exp \left[-\left(\frac{t}{t_{0}}\right)^{n}\right]\right\} .
$$

where $t_{0}$ and $n$ are the desorption median time parameters and the time effect of divergence and $t$ is the time. The above parameters are related to experimental water pressure and type of coal. 


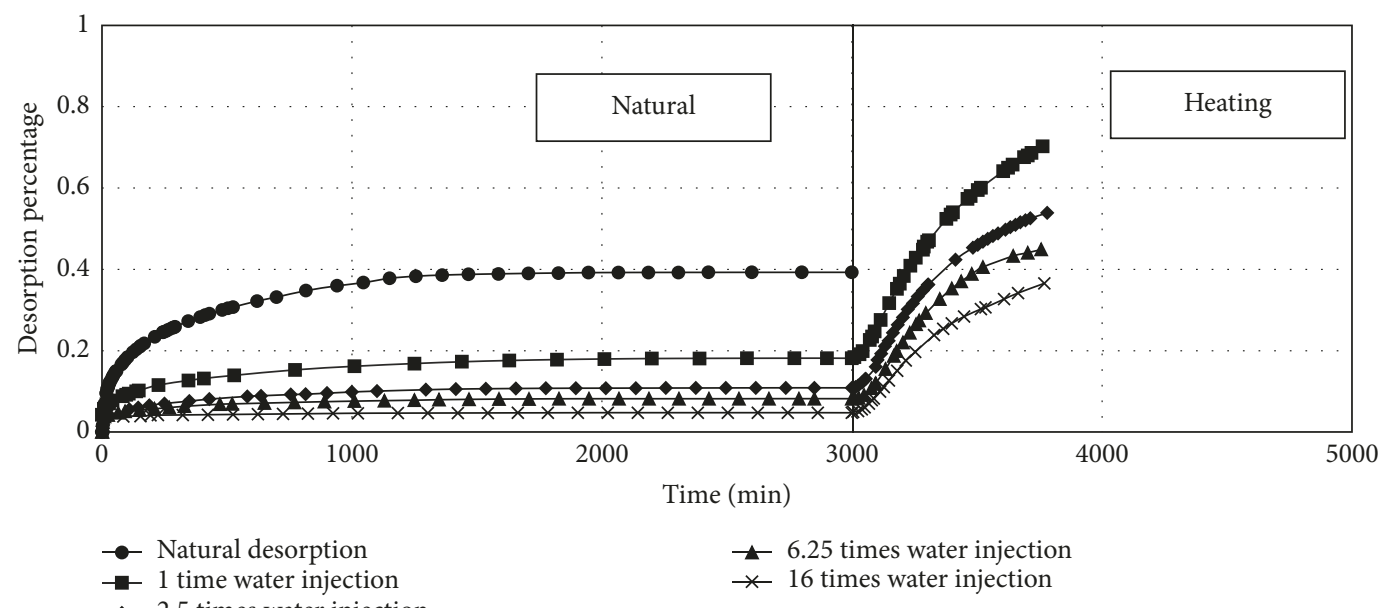

(a)

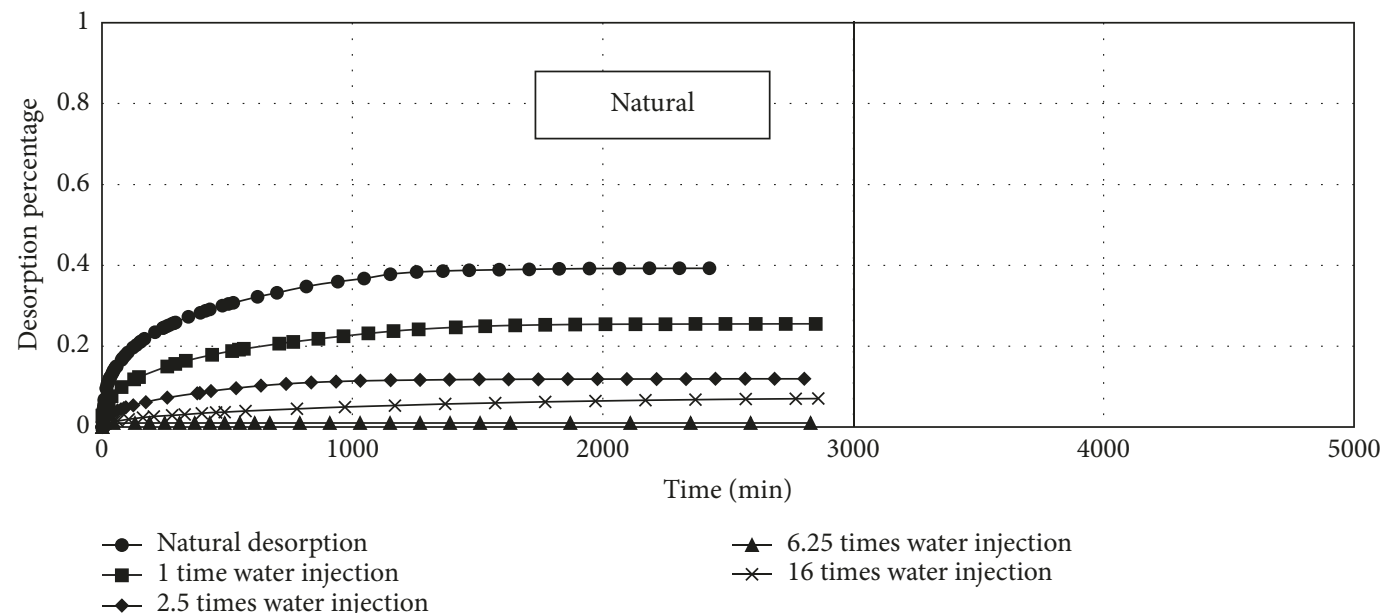

(b)

Figure 4: Desorption capacity versus time in different water injection pressures around 0.50 MPa gas adsorption pressure. (a) Coal sample \#1 (Gucheng Coal Mine). (b) Coal sample \#2 (Gaohe Coal Mine).

Equation (1) is transformed and can be changed to the following equation if $x=t$ :

$$
y=\left(\frac{x}{t_{0}}\right)^{n} .
$$

According to (1) and (2), a regression analysis has been made using the experimental results, and the simulation results are shown in Table 4 . It can be seen that the timedependent parameter $t_{0}$ of desorption gradually increases with the change of water injection pressure, which indicates that high-pressure water injection will affect the desorption rate of coalbed methane.

\subsubsection{The Relationship between Final Desorption Percentage} and Water Injection Pressure. Desorption capacities as a function of water pressure for the two coal samples at $0.25 \mathrm{MPa}$ and $0.50 \mathrm{MPa}$ gas adsorption pressure are shown in Figures 5 and 6, respectively. From natural desorption to 2.5 times water injection pressure and then 6.25 times water injection pressure, the desorption percentage is a gradual change in the slope of the curve, and the data change of water pressure from 6.25 times to 16 times is small and relatively straight. With the increase of multiples of injection pressure, the impact of water injection on the desorption rate is initially severe, and then gradually slows down, and finally approaches an equilibrium state. When the adsorption pressure became greater, the desorption percentage raised for same type of coal samples. This is due to the adsorption of gas that has the greater desorb potential energy and the stronger ability to breakthrough constraint of capillarity for adsorption equilibrium pressure of coal samples so that the coal samples have stronger desorption capacity.

To reveal the final desorption percentage of natural desorption and four different water injection pressures, according to isothermal adsorption-desorption formula, one transformation of it could be introduced on the basis of experimental results of the relationship between the desorption rate and water pressure:

$$
\eta_{\max }=\eta_{\mathrm{dmax}}\left(1-\frac{a P_{2}}{1+b P_{2}}\right)
$$


TABLE 4: Simulation results of time effect on desorption.

\begin{tabular}{|c|c|c|c|c|c|}
\hline Sample number & Adsorption gas pressure & Experimental stage & Simulation results from (1) & Results from (2) & $R^{2}$ \\
\hline \multirow{5}{*}{1} & \multirow{5}{*}{$0.25 \mathrm{MPa}$} & Natural desorption & $\eta=\eta_{\max }\left\{1-\exp \left[-(t / 0.01055)^{0.5393}\right]\right\}$ & $y=0.0859 x^{0.5393}$ & 0.9735 \\
\hline & & 1 time & $\eta=\eta_{\max }\left\{1-\exp \left[-(t / 0.017144)^{0.365}\right]\right\}$ & $y=0.2267 x^{0.365}$ & 0.8843 \\
\hline & & 2.5 times & $\eta=\eta_{\max }\left\{1-\exp \left[-(t / 0.019 .34)^{0.3743}\right]\right\}$ & $y=0.227 x^{0.3743}$ & 0.9244 \\
\hline & & 6.25 times & $\eta=\eta_{\max }\left\{1-\exp \left[-(t / 0.00706)^{0.1796}\right]\right\}$ & $y=0.0256 x^{0.1796}$ & 0.9933 \\
\hline & & 16 times & $\eta=\eta_{\max }\left\{1-\exp \left[-(t / 0.00586)^{0.1079}\right]\right\}$ & $y=2.7378 x^{0.1079}$ & 0.9131 \\
\hline \multirow{5}{*}{1} & \multirow{5}{*}{$0.50 \mathrm{MPa}$} & Natural desorption & $\eta=\eta_{\max }\left\{1-\exp \left[-(t / 0.005252)^{0.6349}\right]\right\}$ & $y=0.0357 x^{0.6349}$ & 0.9617 \\
\hline & & 1 time & $\eta=\eta_{\max }\left\{1-\exp \left[-(t / 0.007177)^{0.493}\right]\right\}$ & $y=0.0877 x^{0.493}$ & 0.9261 \\
\hline & & 2.5 times & $\eta=\eta_{\max }\left\{1-\exp \left[-(t / 0.005283)^{0.5988}\right]\right\}$ & $y=0.0443 x^{0.5988}$ & 0.9534 \\
\hline & & 6.25 times & $\eta=\eta_{\max }\left\{1-\exp \left[-(t / 0.016739)^{0.3604}\right]\right\}$ & $y=0.229 x^{0.3604}$ & 0.8997 \\
\hline & & 16 times & $\eta=\eta_{\max }\left\{1-\exp \left[-(t / 0.086339)^{0.2769}\right]\right\}$ & $y=0.5075 x^{0.2769}$ & 0.8695 \\
\hline \multirow{5}{*}{2} & \multirow{5}{*}{$0.25 \mathrm{MPa}$} & Natural desorption & $\eta=\eta_{\max }\left\{1-\exp \left[-(t / 0.00708)^{0.5592}\right]\right\}$ & $y=0.0628 x^{0.5592}$ & 0.9836 \\
\hline & & 1 time & $\eta=\eta_{\max }\left\{1-\exp \left[-(t / 0.00606)^{0.5977}\right]\right\}$ & $y=0.0473 x^{0.5977}$ & 0.9464 \\
\hline & & 2.5 times & $\eta=\eta_{\max }\left\{1-\exp \left[-(t / 0.0011393)^{1.359}\right]\right\}$ & $y=0.0001 x^{1.359}$ & 0.9723 \\
\hline & & 6.25 times & $\eta=\eta_{\max }\left\{1-\exp \left[-(t / 0.001420)^{1.2372}\right]\right\}$ & $y=0.0003 x^{0.1 .2372}$ & 0.9006 \\
\hline & & 16 times & $\eta=\eta_{\max }\left\{1-\exp \left[-(t / 0.007109)^{0.3814}\right]\right\}$ & $y=0.1516 x^{0.3814}$ & 0.8335 \\
\hline \multirow{5}{*}{2} & \multirow{5}{*}{$0.50 \mathrm{MPa}$} & Natural desorption & $\eta=\eta_{\max }\left\{1-\exp \left[-(t / 0.005252)^{0.6349}\right]\right\}$ & $y=0.0357 x^{0.6349}$ & 0.9617 \\
\hline & & 1 time & $\eta=\eta_{\max }\left\{1-\exp \left[-(t / 0.005112)^{0.6054}\right]\right\}$ & $y=0.041 x^{0.6054}$ & 0.9536 \\
\hline & & 2.5 times & $\eta=\eta_{\max }\left\{1-\exp \left[-(t / 0.0054527)^{0.622}\right]\right\}$ & $y=0.0391 x^{0.622}$ & 0.9611 \\
\hline & & 6.25 times & $\eta=\eta_{\max }\left\{1-\exp \left[-(t / 0.001430)^{1.0708}\right]\right\}$ & $y=0.0009 x^{1.0708}$ & 0.9475 \\
\hline & & 16 times & $\eta=\eta_{\max }\left\{1-\exp \left[-(t / 0.006566)^{0.512}\right]\right\}$ & $y=0.0026 x^{0.512}$ & 0.9164 \\
\hline
\end{tabular}

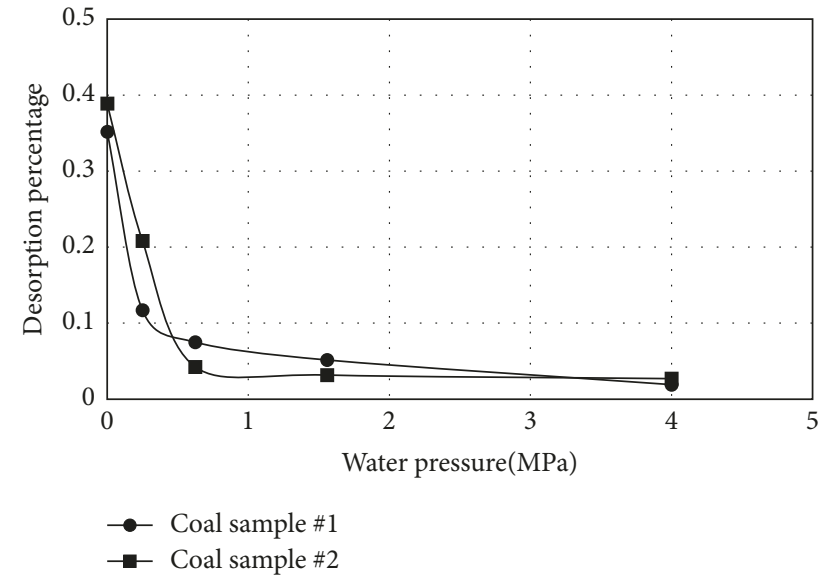

FIGURE 5: Desorption capacity as a function of water pressure for the two coal samples at $0.25 \mathrm{MPa}$ gas adsorption pressure.

where $\eta_{\mathrm{dmax}}$ is the final desorption percentage (\%) of the coal sample during natural desorption and $a$ and $b$ are the related parameters $\left(\mathrm{MPa}^{-1}\right)$.

Equation (3) can be changed into the following form if $y=\eta_{\mathrm{dmax}} /\left(\eta_{\mathrm{dmax}}-\eta_{\max }\right), x=1 / P_{4}$ :

$$
y=\frac{1}{a} x+\frac{b}{a}
$$

The regression analysis of the experimental results and simulation results shows in Table 5 that $b / a$ is one of the

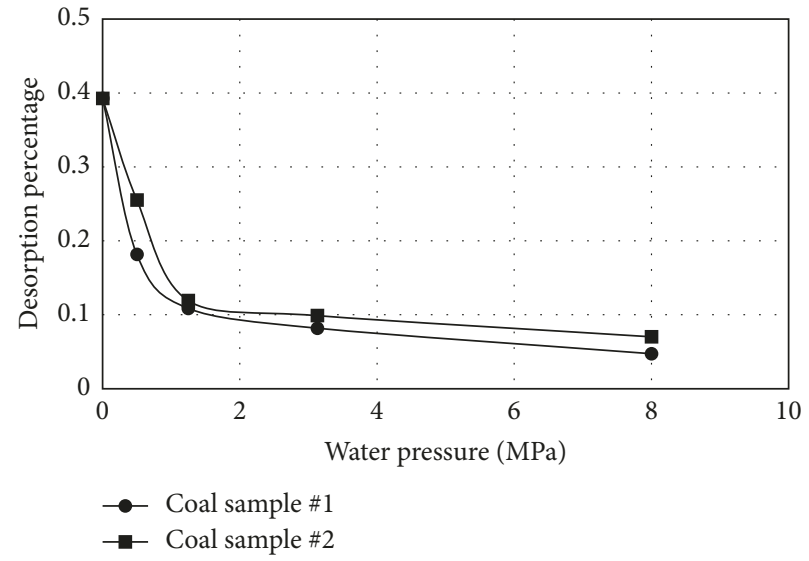

FIGURE 6: Desorption capacity as a function of water pressure for the two coal samples at $0.50 \mathrm{MPa}$ gas adsorption pressure.

important indexes to measure the effect of water injection on gas desorption and the lower limiting value is 1 , indicating that the gas desorption rate is equal to 0 when the water pressure is infinite. The value of $b / a$ is close to 1 in this paper, indicating that the desorption rate of gassy coal will decrease with the increase of external moisture injection pressure. The desorption rate will be close to zero when the water pressure increases to a certain value.

The influence of moisture on coal desorption based on coal moisture content by using small particle size coal samples had been revealed in following form [20]: 
TABLE 5: Simulation results between desorption percentage and water injection pressure.

\begin{tabular}{lcccc}
\hline Sample number & Adsorption gas pressure & Simulation results of $(3)$ & Simulation results of $(4)$ & \multicolumn{1}{c}{$R^{2}$} \\
\hline 1 & $0.25 \mathrm{MPa}$ & $\eta_{\max }=\eta_{\text {dmax }}\left(1-2.2492 P_{4} /\left(1+2.1641 P_{4}\right)\right)$ & $y=0.4446 x+1.0393$ & 0.9896 \\
2 & $0.50 \mathrm{MPa}$ & $\eta_{\max }=\eta_{\text {dmax }}\left(1-0.7251 P_{4} /\left(1+0.6699 P_{4}\right)\right)$ & $y=1.379 x+1.0824$ & 0.9591 \\
1 & $0.25 \mathrm{MPa}$ & $\eta_{\max }=\eta_{\text {dmax }}\left(1-1.2318 P_{4} /\left(1+1.1777 P_{4}\right)\right)$ & $y=0.8118 x+1.0459$ & 0.9877 \\
2 & $0.50 \mathrm{MPa}$ & $\eta_{\max }=\eta_{\text {dmax }}\left(1-0.9689 P_{4} /\left(1+0.9617 P_{4}\right)\right)$ & $y=1.032 x+1.0075$ & 0.9565 \\
\hline
\end{tabular}

$$
\eta_{\mathrm{d}}=\eta_{\mathrm{dmax}}\left(1-\frac{0.032 M}{1+1.152 M}\right)
$$

where $M$ is the water content (\%).

This formula is similar to this study. The water content of coal is positively correlated with the water injection pressure and can be approximated by comparison, but the value of $b / a$ that has been obtained is larger, indicating that the desorption rate is still about $4 / 5$ at natural desorption when reaching saturated water content. The smaller the particle size of the coal samples is, the less the impact of external water injection on the desorption of coal is.

\section{Discussion}

The essence of gas drainage is the conversion process of gas from adsorption to free state, and this process must involve two physical quantities which are gassy potential and chemical potential produced by coalbed methane adsorption [21]. The matter always tends to transform from a state with high chemical potential to a low one. Both reducing the pressure and increasing the temperature reduce the chemical potential of the free gas, which is favorable for the gas to be converted from the adsorbed state to the free state. Gas adsorption potential is to reflect the coal surface adsorption capacity of the methane. The larger the adsorption potential energy is, the less it is easily desorbed. And the higher the temperature is, the lower the adsorption potential energy is. In view of this, adsorption pressure and desorption temperature are inevitably important factors that affect the gas from adsorption to free state transformation. Desorption capacity as a function of water pressure at $90^{\circ} \mathrm{C}$ for coal sample \#1 is shown in Figure 7. Temperature has a promoting effect on gas desorption, and it is different from various water injection pressures.

On the other hand, $80 \%-90 \%$ of methane in the actual coal seam is occluded in the pores and fissures of the coal body in the adsorbed state. Therefore, the pores and fissures are also the important factors that affect the gas desorption. The main factor of the conditions of coal seam and pore is moisture in the actual coal mine production. In summary, the pressure, temperature, and pore fissures are the key conditions for studying methane desorption. In this paper, the above conditions are studied by changing adsorption pressure, desorption temperature, and multiples of injection pressure. In these experiments, coal samples reached the wet state after desorption in different water injection pressures. The mass of coal samples as a function of water pressure after desorption for coal sample $\# 2$ is shown in Figure 8 . The moisture in the samples is the dominating role for increasing the mass.

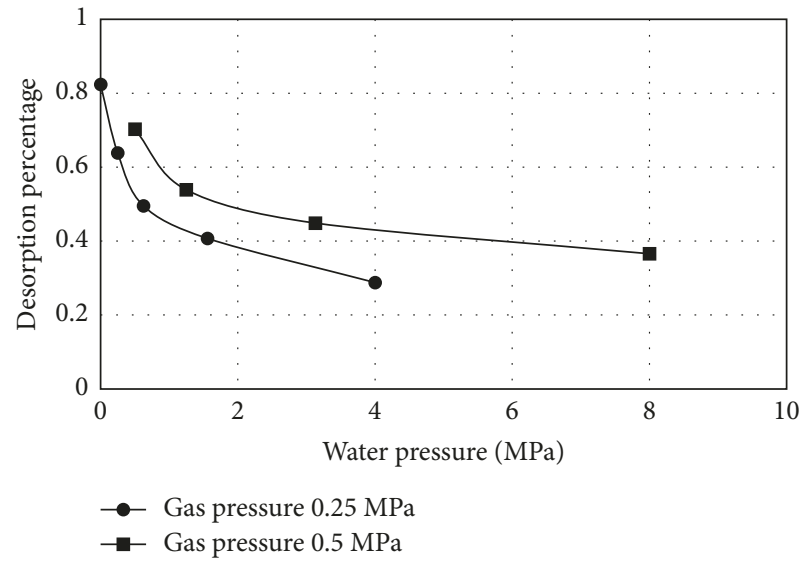

FIgURE 7: Desorption capacity as a function of water pressure at $90^{\circ} \mathrm{C}$ for coal sample \#1.

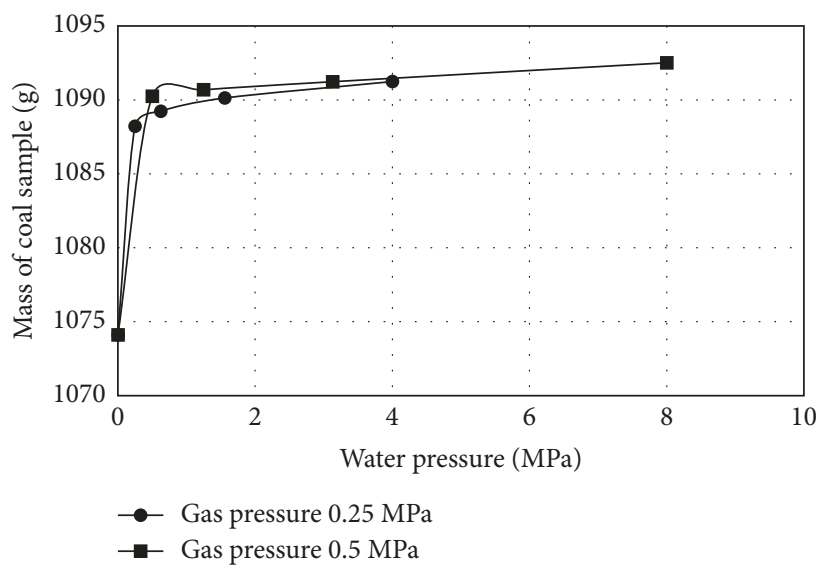

FIGURE 8: Mass of the coal sample as a function of water pressure after desorption for coal sample \#2 (the initial mass of the coal sample is $1074.1 \mathrm{~g}$ before experiment).

The larger the adsorption pressure it has, the greater the desorption pressure it will reduce, and it will be more favorable to the release of chemical potential energy and will get higher desorption rate. In this paper, $0.2 \mathrm{MPa}$ adsorption pressure desorption rate was significantly higher than $0.1 \mathrm{MPa}$ adsorption pressure. The heating process of Gucheng coal samples is very significant that the process of heating promoted the desorption. In this paper, it can be seen from the research of different moisture injection pressure conditions that the desorption rate is getting lower and lower with the increase of moisture injection pressure because the moisture molecules obviously block the pores and cracks in the coal through water injection and the amount of desorption energy of the molecule greatly increases, so the 
greater the pressure of water injection is, the more difficult it is for the gas in the pore fissure to desorb. Throughout all the experiments, it can be confirmed that moisture injection can effectively suppress the gas desorption process.

\section{Conclusion}

In this paper, based on the desorption characteristics of gasbearing coal under different conditions, a lot of corresponding experiments have been done. We got the change regulation of desorption characteristics of gassy coal which was under different moisture injection pressures, different adsorption pressures, and different temperatures. The results show the following:

The samples of Gucheng and Gaohe Coal Mine under adsorption pressure around $0.25 \mathrm{MPa}$ and $0.50 \mathrm{MPa}$ have different desorption capacities with different water injection pressures; $2.5,6.25$, and 16 times water injection conditions are $32.79 \%, 16.59 \%, 11.94 \%$, and $5.29 \% ; 46.66 \%, 24.03 \%$, $17.26 \%$, and $9.29 \%$ (Gucheng) and 56.01\%, 17.33\%, 7.32\%, and $0.94 \% ; 52.07 \%, 22.27 \%, 15.76 \%$, and $12.76 \%$ (Gaohe).

Heating can effectively promote gas desorption, and with the increase of water injection multiples, the promotion of heating on the desorption was more obvious. For the desorption rate in heating, equal pressure water injection, 2.5, 6.25 and 16 times water injection increased about 6 times, 6 times, 7 times, and 21 times, respectively.

There is a certain time-median effect on the desorption of coal gas along with time after water injection, and it will vary with the water injection pressure. Under different water injection pressures, the final desorption rate of coalbed methane under different moisture injection pressures and natural desorption under the same conditions has a certain functional relationship.

\section{Conflicts of Interest}

The authors declare that there are no conflicts of interest regarding the publication of this paper.

\section{Acknowledgments}

This research was supported by the National Natural Science Foundation of China (Grant nos. 51304142 and 21373146) and by the Program for Outstanding Innovation Teams of Higher Learning Institutions of Shanxi (Grant Year 2014).

\section{References}

[1] F. Zhou, T. Xia, X. Wang, Y. Zhang, Y. Sun, and J. Liu, "Recent developments in coal mine methane extraction and utilization in China: a review," Journal of Natural Gas Science and Engineering, vol. 31, pp. 437-458, 2016.

[2] J. H. Fu and Y. P. Cheng, "The coal and gas outburst situation and prevention solutions in China coal mine," Mining and Safety Engineering Journal, vol. 24, pp. 253-259, 2007.

[3] Y. Li, Y. F. Chen, and C. B. Zhou, "Effective stress principle for partially saturated rock fractures," Rock Mechanics and Rock Engineering, vol. 49, no. 3, pp. 1091-1096, 2016.

[4] S. Chen, T. Yang, P. G. Ranjith, and C. Wei, "Mechanism of the two-phase flow model for water and gas based on adsorption and desorption in fractured coal and rock," Rock Mechanics and Rock Engineering, vol. 50, no. 3, pp. 571-586, 2017.

[5] D. Zhao, Z. Feng, and Y. Zhao, "Laboratory experiment on coalbed-methane desorption influenced by water injection and temperature," Journal of Canadian Petroleum Technology, vol. 50, pp. 24-33, 2011.

[6] X. Jianlin, Z. Yangsheng, L. Xiangchun et al., “The experiment of gas adsorption and desorption under the action of high temperature and high pressure water," Procedia Engineering, vol. 26, pp. 1547-1553, 2011.

[7] Z. Shi-yin and S. Shu-xun, "Physical chemistry mechanism of influence of liquid water on coalbed methane adsorption," Procedia Earth and Planetary Science, vol. 1, no. 1, pp. 263268, 2009.

[8] Z. Pakowski, R. Adamski, M. Kokocińska, and S. Kwapisz, "Generalized desorption equilibrium equation of lignite in a wide temperature and moisture content range," Fuel, vol. 90, no. 11, pp. 3330-3335, 2011.

[9] X. Zhiguo and W. Zhaofeng, "Experimental study on inhibitory effect of gas desorption by injecting water into coalsample," Procedia Engineering, vol. 26, pp. 1287-1295, 2011.

[10] D. F. Zhang, Y. J. Cui, S. G. Li, W. L. Song, and W. G. Lin, "Adsorption and diffusion behaviors of methane and carbon dioxide on various rank coals," Journal of China Coal Society, vol. 35, no. 10, pp. 1963-1968, 2011.

[11] X. Chen and Y. Chen, "Influence of the injected water on gas outburst disasters in coal mine," Natural Hazards, vol. 76, no. 2, pp. 1093-1109, 2015.

[12] Z. W. Chen, J. S. Liu, D. Elsworth, L. D. Connell, and Z. J. Pan, "Impact of $\mathrm{CO}_{2}$ injection and differential deformation on $\mathrm{CO}_{2}$ injectivity under in-situ stress conditions," International Journal of Coal Geology, vol. 81, no. 2, pp. 97-108, 2010.

[13] H. Wang, H. Merry, G. Amorer, and B. Kong, "Enhance hydraulic fractured coalbed methane recovery by thermal stimulation," in Proceedings of the SPE/CSUR Unconventional Resources Conference on Society of Petroleum Engineers. SPE 175927, Muscat, Oman, January 2015.

[14] Y. Song, C. Cheng, J. Zhao et al., "Evaluation of gas production from methane hydrates using depressurization, thermal stimulation and combined methods," Applied Energy, vol. 145, pp. 265-277, 2015.

[15] Y. Lin, H. Y. Wang, S. He, and M. Nikolaou, "Increasing shale gas recovery through thermal stimulation: analysis and an experimental study," in Proceedings of the SPE Annual Technical Conference and Exhibition. SPE 175070, Houston, TX, USA, September 2015.

[16] A. Shahtalebi, C. Khan, A. Dmyterko, P. Shukla, and V. Rudolph, "Investigation of thermal stimulation of coal seam gas fields for accelerated gas recovery," Fuel, vol. 180, pp. 301-313, 2016.

[17] N. B. Yahya, M. Kashif, N. Nasir, M. N. Akhtar, and N. M. Yusof, "Cobalt ferrite nanoparticles: an innovative approach for enhanced oil recovery application," Journal of Nano Research, vol. 17, pp. 115-126, 2012.

[18] A. Salmachi and M. Haghighi, "Feasibility study of thermally enhanced gas recovery of coal seam gas reservoirs using geothermal resources," Energy \& Fuels, vol. 26, no. 8, pp. 5048-5059, 2012.

[19] H. Bahrami, R. Rezaee, and B. Clennell, "Water blocking damage in hydraulically fractured tight sand gas reservoirs: an example from Perth Basin, Western Australia," Journal of Petroleum Science and Engineering, vol. 88-89, pp. 100-106, 2012. 
[20] Z. F. Wang, X. H. Li, and L. L. Qi, "The study of the moisture effect on gas desorption speed of Yangquan anthracite," Mining Safety, vol. 429, no. 7, pp. 1-3, 2010.

[21] Q. Liu, Y. Cheng, H. Zhou, P. Guo, F. An, and H. Chen, “A mathematical model of coupled gas flow and coal deformation with gas diffusion and Klinkenberg effects," Rock Mechanics and Rock Engineering, vol. 48, no. 3, pp. 1163-1180, 2014. 


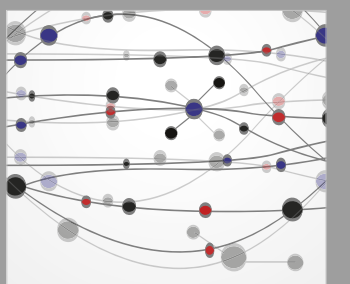

The Scientific World Journal
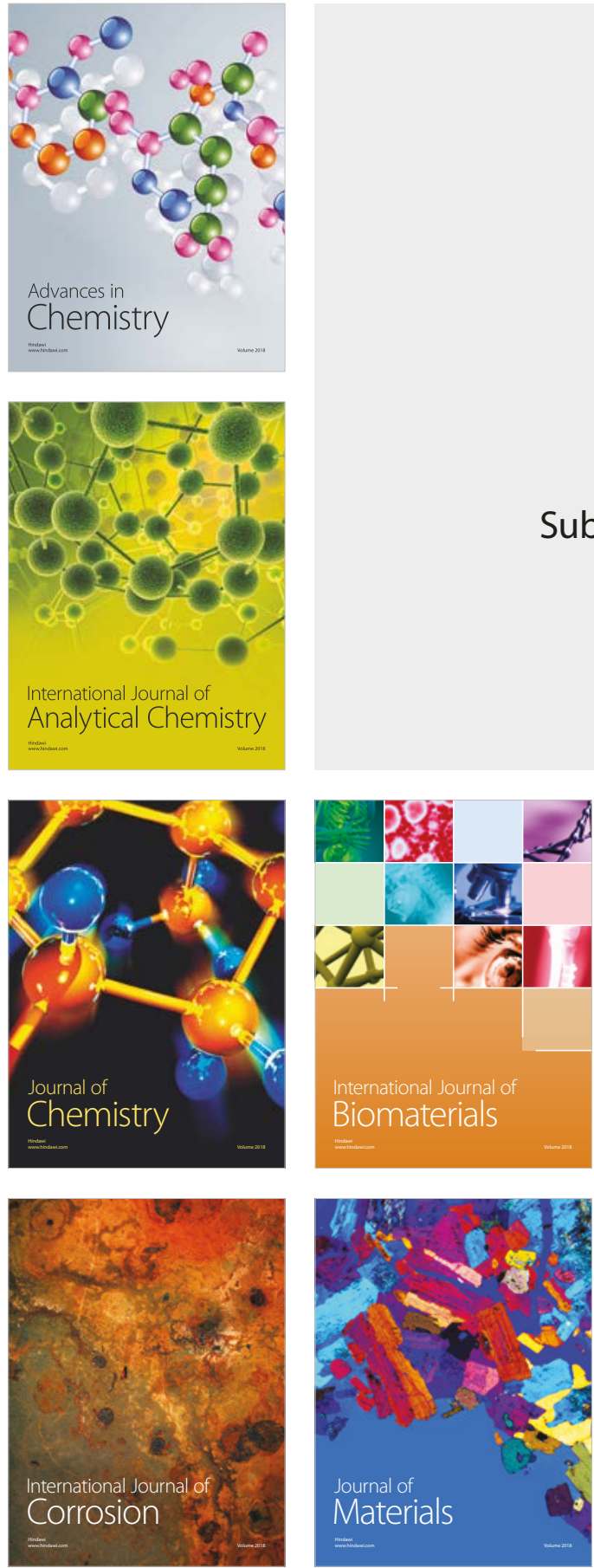

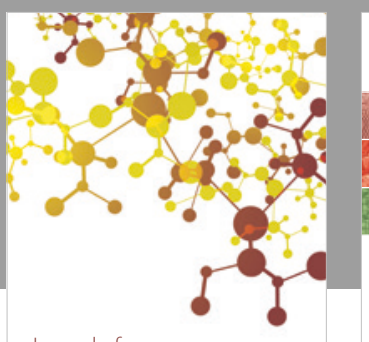

Journal of

Applied Chemistry
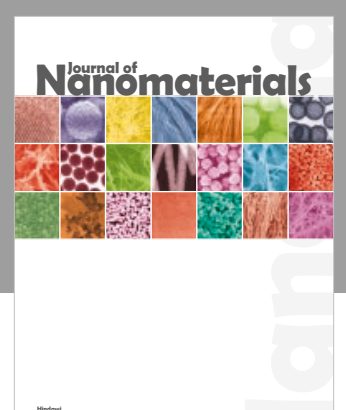

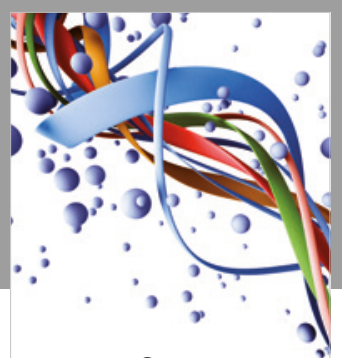

Scientifica

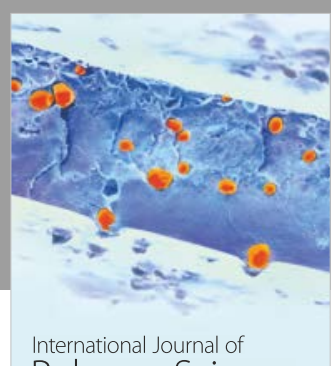

Polymer Science

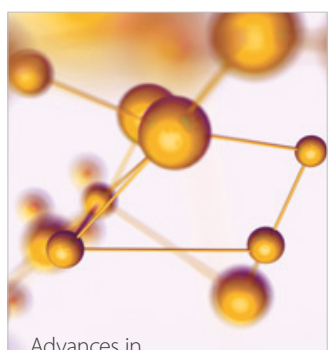

Physical Chemistry
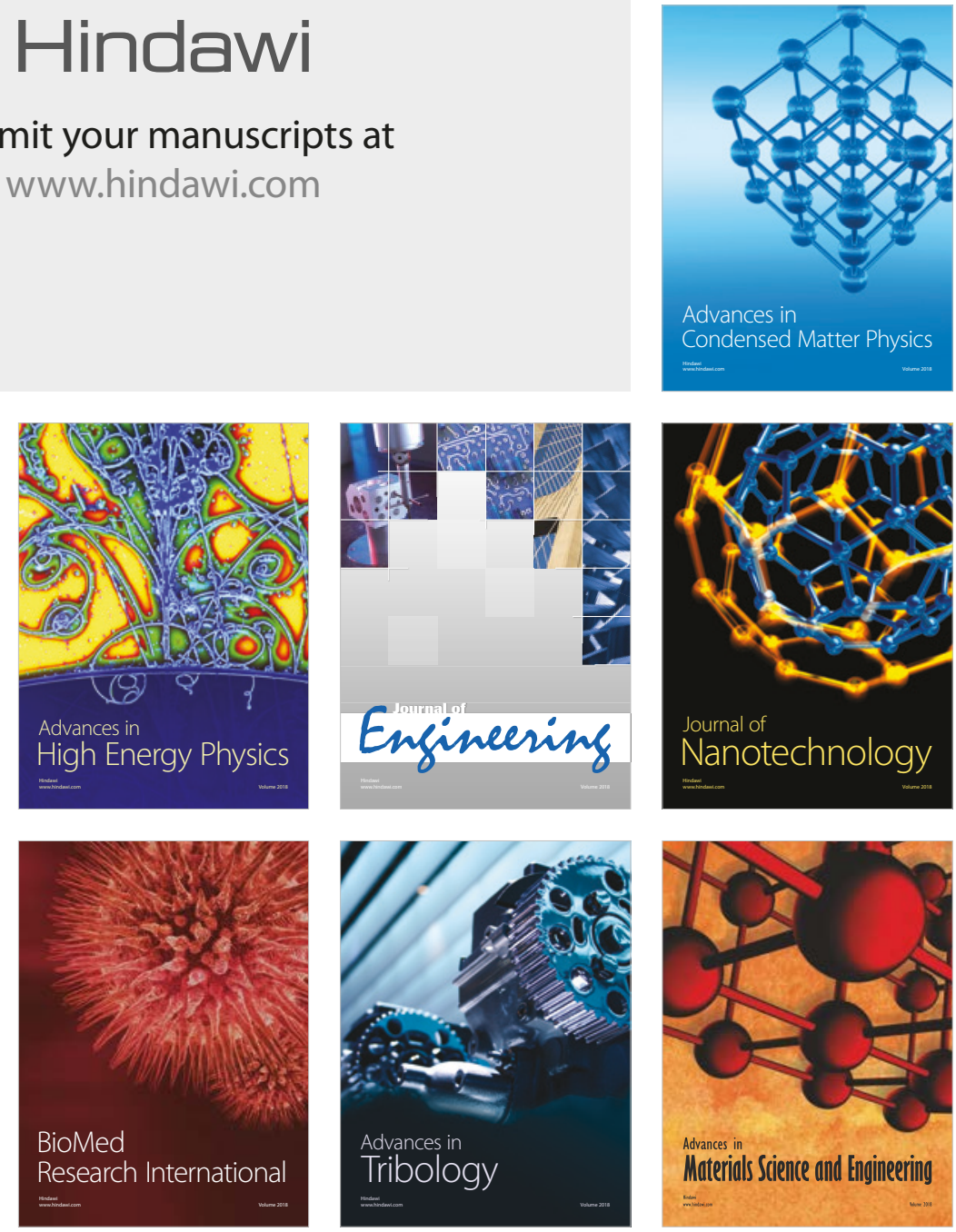